\title{
Machine learning based multi class fault diagnosis tool for voltage source inverter driven induction motor
}

\author{
Jyothi R, Tejas Holla, Uma Rao K, Jayapal R \\ Department of Electrical and Electronics Engineering, RV College of Engineering, Bengaluru, india
}

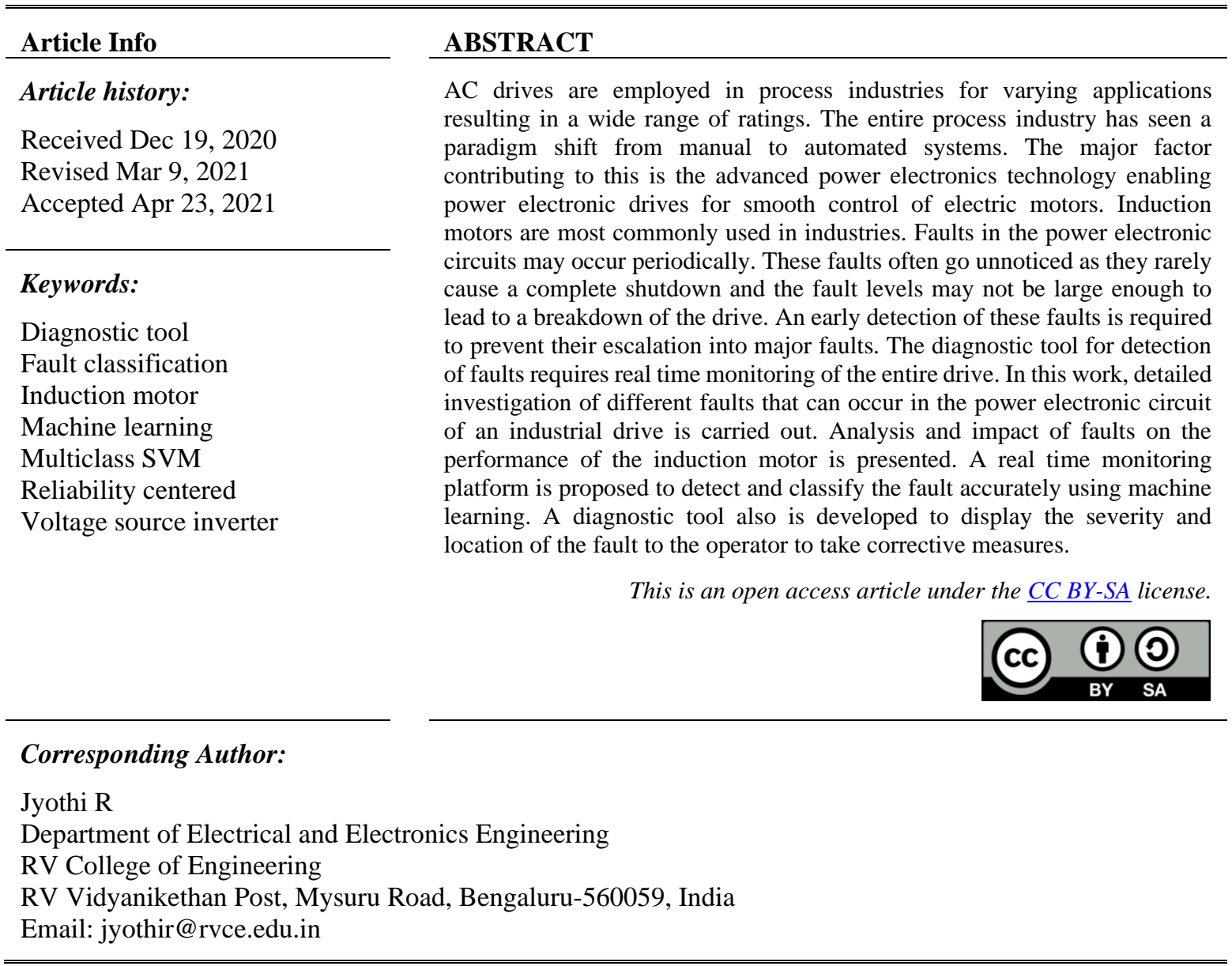

\section{INTRODUCTION}

Induction motors are rugged in construction and are used in driving lathe machines, crushers, oil extracting mills, textile industries, etc. For the smooth control of the induction motors, power electronic converters are employed. In process industries and manufacturing sectors, the monitoring of power electronic systems is essential as it affects the system's performance and efficiency. The faults in the system are to be identified on occurrence to avoid complete breakdown of the production process. Most of the organizations now a days follow preventive maintenance by scheduling periodical maintenance before failure occurs and causes damage to the entire system under consideration. If the preventive maintenance is scheduled early, it might lead to wastage of useful life of machine. An alternative approach is reliability centered maintenance. reliability centered maintenance is chosen to optimize the maintenance program by monitoring the essential parameters and recognizing the faults that affects the function of an AC drive system. Due to heavy downtime costs of devices in modern power industries, there is a need for real time monitoring system to detect incipient faults before they escalate and casue a breakdown.

Much of the research presented in the literature is focused on the detection of faults in the induction motor such as rotor bar fault, eccentricity fault. Conventional approaches like motor current signature analysis 
(MCSA) techniques were employed in earlier days for fault diagnosis in three phase induction motors. Fault feature was extracted through fast fourier transform (FFT) from sampled stator currents to train the model using multilayer perceptron, support vector machine (SVM) [1], [7], [8]. Rule based approach like fuzzy logic technique was employed for fault detection in the Induction motors [2]-[6]. Discrete wavelet transform (DWT) [8], [9] and principal component analysis (PCA) were utilized to identify the discontinuity in the feature caused by the faults. Relevance vector machine (RVM) with optimization techniques like evolutionary particle swarm optimization, cuckoo search optimization was employed to improve the fault detection as the DWT involves huge data and computational time [7], [13]. Clarke transformed two dimensional features along with surface error were used to detect the fault. Average current of the three stator currents also was used to detect the faults in the system [11]-[15].

Detailed diagnostic tool for exhaustive faults in the power electronics drive of an induction motor is not found in the literature. In this work, the various faults that are likely to occur in the power electronics circuits have been investigated to detect and classify the faults accurately and identify the correct location of the faults. The number of features has been optimized to improve the efficiency of the diagnostic tool and also enable its adaptation for a real time monitoring. Two machine learning algorithms namely multilayer perceptron neural network and support vector machine have been found to give accurate results. 100 percent accuracy has been achieved for detection, classification and location of the fault. Similar applictaions discussed in literature use labview and intricate hardware set up. The novelty of this present work is the use of IoT and minimal sensors for remote monitoring of the devices. Also, a user-friendly GUI has been developed to display the results as an operating tool. Reliability centered maintenance would go long way with such a diagnostic tool reducing loss of production time.

The paper is divided into 8 Sections. Section 1 focuses on the different maintenance strategy and the conventional methods available for fault diagnosis. In Section 2, the structure of the drive and various faults are presented. Fault detection and classification methodology used is presented in section 3. Section 4 presents the simulation model and the feature acquisition. Hardware set up and its specifications are mentioned in the Section 5. Results and discussion are presented in Section 6. Diagnostic tool with case studies is presented in Section 7 and conclusion is presented in Section 8.

\section{FAULTS IN AN AC DRIVE SYSTEM}

Figure 1 represents the structure of voltage source inverter driven induction motor. It consists of the three phase AC supply, controlled or uncontrolled rectifier, DC link and an inverter capable of generating variable voltage and variable frequency with PWM pulses.different types of PWM techniques and the modulation index will have impact on inverter line output voltages and stator currents [18], [19]. The three phase supply is connected to a diode bridge rectifier to produce DC voltage at the front end . The rectified voltage is fed through DC link to the power inverter circuit consisting of sensitive power electronic switching devices such as IGBTs or MOSFETs which are driven by gate drive circuits to provide variable voltage and frequency to the dynamic loads for speed control. The power electronic circuitry employed in AC drives are liable to numerous types of electrical faults such as faults in the rectifier, inverter, faults at the motor terminals and faults in the mechanical load as detailed.

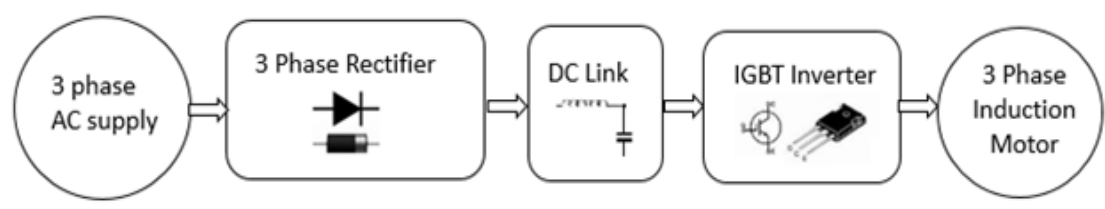

Figure 1. Structure of voltage source inverter driven induction motor

\subsection{Faults in rectifier}

Bridge rectifiers are used in most of the industrial drives. Faults in an uncontrolled bridge rectifier can be categorized as open diode fault and diode short circuit fault. In case of open diode fault the magnitude of the DC output voltage of the rectifier reduces thus affecting performance of the inverter circuit. If diodes of the same leg are shorted, the current through the circuit shoots up swiftly and potential difference across the diodes reduces to zero. Due to short circuit of DC Link capacitors at the rectifier front end, faults can occur in the drive system [20]. 


\subsection{Faults in inverter}

In general, variable voltage variable frequency inverters are preferred over current source inverters, for drives. Inverters are also susceptible to open circuit and short circuit IGBT faults. Protection schemes will be employed for short circuit faults. In case of open IGBT fault, the motor will still be in running condition but at reduced speed [20]-[22]. The harmonics component in the stator current of corresponding phase increases resulting in a lower efficiency due to PQ disturbance. Short circuit fault of IGBT results in large amount of current flow through the inverter circuit.

\subsection{Faults at motor terminal}

The three-phase variable frequency, variable output voltage from the VSI is fed to the three-phase motor input terminal. Faults like SLG fault, L-L fault, lines open fault at the AC power line could cause disturbances at the motor terminal. In case of short circuit of the lines, the induction motor will stop running and very high current flows through the short-circuited terminals and the reverse current causes damage to the diodes and IGBTs.

Faults can also occur in the induction motor due to damage in stator windings, bearings, squirrel cage rotor broken bars, insulation failure [21]-[23]. The incipient faults do not cause the motor to stop unlike short circuit faults. The induction motors operate even on the occurrence of incipient faults. The reliability of the entire system tend to reduce and damage the machines over the long run. Hence, they are dangerous as they may be undetected for a long time, silently causing damage to the motor.

Fault diagnosis plays a crucial role in industrial processes which involves fault detection and classification (FDC) based on location and its severity. The operator also needs to be informed about the fault through an interface to take precautionary measures or to take immediate action to avoid the consequences of failure and damage to the machine. The entire process is termed as reliability centered maintenance. Amongst numerous approaches followed for the reliability centered maintenance, machine learning appears to be an encouraging tool.

In the proposed work, two machine learning algorithms namely multi-layer perceptron-neural network (MLP-NN) and support vector machine (SVM) are employed [22]. Data acquisition is performed through multiple sensors to monitor the condition of the power electronic system. Often the data collected through physical sensors may not yield good feature extraction. In such cases, additional features are generated using the measured data to obtain the hidden features. This data is termed as synthesized data.

In the proposed work, AC drive is simulated using MATLAB/Simulink. Various types of open circuit faults such as diode open fault in the rectifier, open IGBT fault in the inverter are created and corresponding electrical parameters like stator currents, inverter line output voltages and their THDs and the mechanical parameters like speed and torque of the motor are obtained to determine the effect of the electrical faults. Fault's detection, classification and point of occurrence of fault are identified using machine learning and diagnostic tool is developed using python to display the information about the severity of fault to the operator to take corrective measures.

\section{FAULT DETECTION AND CLASSIFICATION SYSTEM}

The block diagram of fault detection and classification (FDC) system is as shown in Figure 2. Machine learning based FDC system involves the steps. The data collection from the system, feature engineering which involves the identification of parameters that are efficient in the detection of faults, data training and choosing a suitable model, training and evaluating the model and parameter tuning for efficient prediction and diagnosis of faults in the system. The raw data collected from the system is not often suitable to train the model and evaluate the parameters for classification of faults. Hence, feature engineering plays a significant role in the fault detection and classification. For a real time, monitoring tool, the features have to be optimized to improve computational power, memory usage and result in shorter training time with minimal chance of overfitting. Classification of faults from the selected features is known as supervised learning approach.

The different machine learning algorithms applicable for classification of the faults in the system are linear classifiers like logistic regression, decision tree, support vector machine and neural network. Multiclass support vector machine algorithm has been extensively used for classification and outlier detection in many applications. Multilayer perceptron neural network (MLP-NN) algorithm consists of set of software neurons arranged in layers with an organized connection for communication. MLP-NN uses gradient descent algorithm for learning through loss function. In the current research work, MLP-NN and SVM are preferred for quantitative multi class electrical fault detection and classification. 


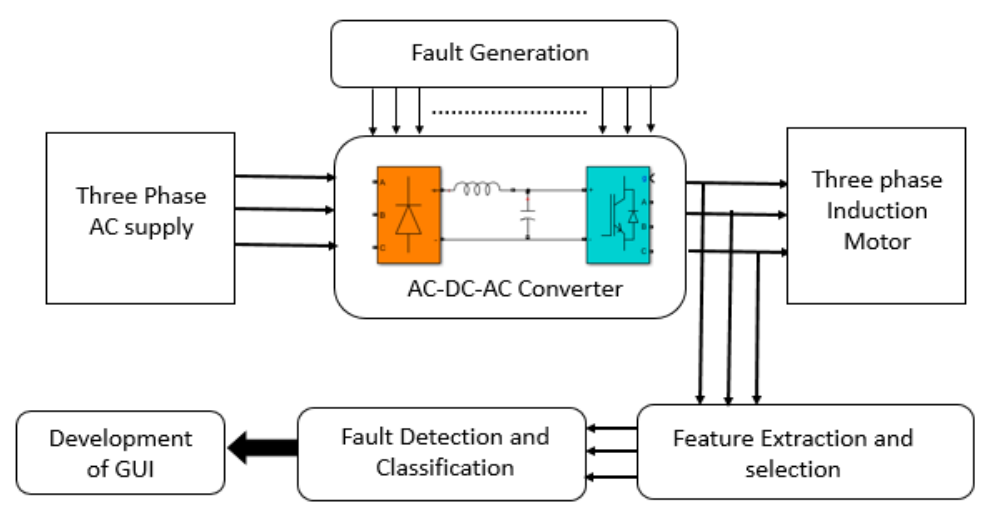

Figure 2. Fault detection and classification system

\section{SIMULATION MODEL}

Fault detection and classification system developed for voltage source inverter driven induction motor (VSI-IM) are discussed in this section. The simulation is carried out in MATLAB/Simulink platform, the data extracted is trained and tested in google colab environment for both the machine learning algorithms namely MLP-NN and SVM. Two different indicators are discussed for fault detection and classification in the VSI-IM system.one using instantaneous values of the parameters and another using RMS Values. The Simulink model used for extracting the data from voltage source driven induction motor is as shown in Figure 3.

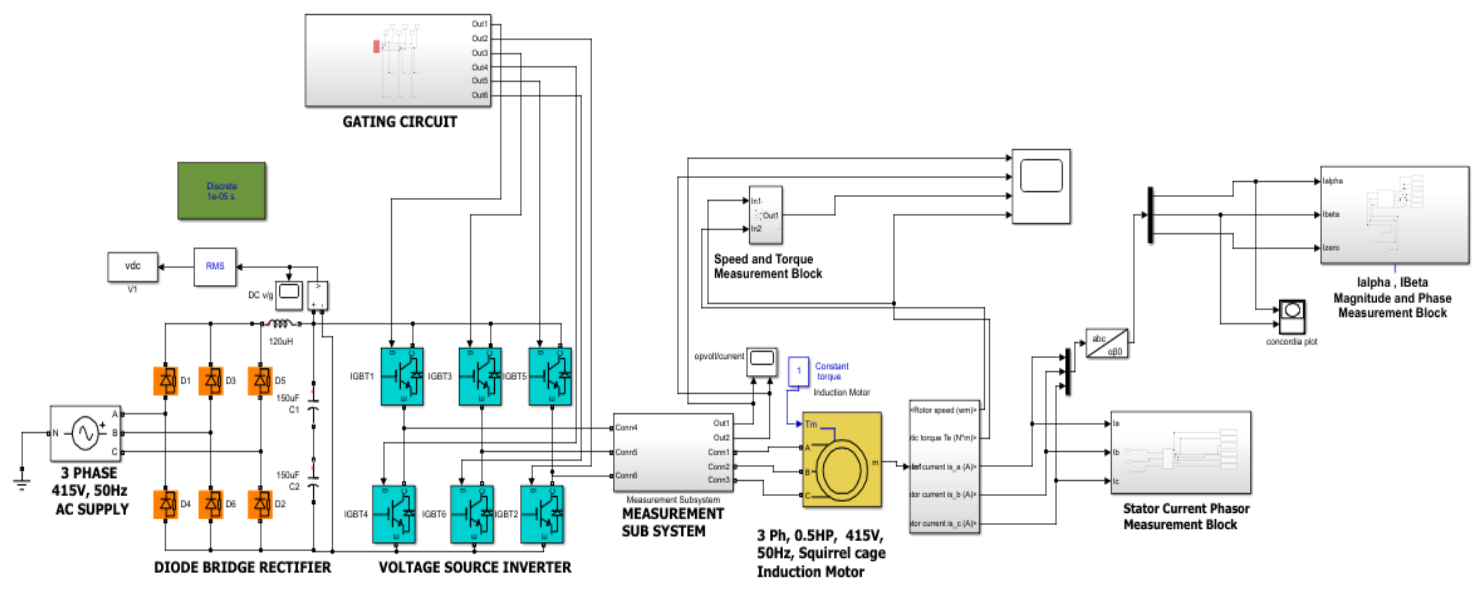

Figure 3. Simulink model of VSI driven Induction motor

The severity of open circuit incipient faults is a major concern, Various open circuit faults are diode open circuit, IGBT open circuit, cross diode and cross IGBT open circuit faults. These are divided into 24 classes. Features are used to distinguish between the various faults. Features such as, i) rectifier output voltage (Vdc), ii) inverter line output voltages (Vab, Vbc, Vca), iii) induction motor stator currents $\left(I_{a}, I_{b}, I_{c}\right)$, iv) the inverter line output voltages and stator currents THDs, and v) speed are used for fault detection and classification using machine learning algorithms [15], [16]. The data is obtained from the simulation model as shown in Figure 3 built using MATLAB 2019a Simulink platform by creating various types of faults at a sampling frequency of $1 \mathrm{e}-5$ seconds. The nature of the data tried for accurate detection and classification are of two types. The data is preprocessed by normalisation technique.

a. Instantaneous values

The instantaneous values of inverter output line voltages and induction motor stator currents and the rectified output voltage and THDs are taken for a window of 1 second with the faults persistent throughout the window. The limitation of instantaneous values for feature extraction is the voluminous size of the data. This would be a major disadvantage for real time application. Hence investigation was carried out to reduce the number of features without sacrificing the classification accuracy. It was observed that three features 
namely the three stator currents are sufficient for detection and classification. Other features are found to be redundant.

b. RMS values

In this approach, RMS values of the stator current phasors were used instead of instantaneous values. Hence the total number of features were six, as each phasor is represented by magnitude and its angle.

\section{HARDWARE}

The hardware set up of VSI driven induction motor is as shown in Figure 4. Two switches were employed to create cross diode open circuit faults and the gating pulses were removed to the IGBTs to create open circuit IGBT faults. The specifications of the hardware set up for extraction of current features is as mentioned in the table 1. The stator current RMS data was extracted from the VSI driven system through ubidots IoT platform. It was observed to be in validation with the simulation data.

Table 1. Specifications of theVSI driven induction motor

\begin{tabular}{ll}
\hline Components & Details \\
\hline Diodes & 6 Nos. 1200V, 30A (for three phase Diode Bridge rectifier)-RHRG30120 \\
DC Link Capacitor & $100 \mathrm{uF}$ \\
IGBT & $6 \mathrm{Nos}$. 1200V, 50A (for Voltage Source Inverter)-KGT25N120KDA \\
Microcontroller & Arduino Uno \\
sensors & 3 Nos. Hall effect Current sensors -ACS716w, Temperature sensor-DTH11 \\
Wi-Fi module & ESP8266 Nodemcu \\
IoT Platform & Ubidots \\
\hline
\end{tabular}

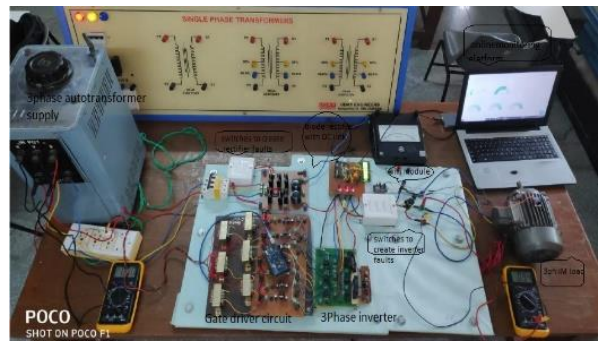

Figure 4. Voltage Source inverter driven induction motor hardware set up

\section{RESULTS AND DISCUSSION}

The various dimensions of the algorithms for the fault detection and classification are:

a. Type of machine learning

Two types are used namely multi layer perceptron-neural network (MLP-NN) and support vector machine (SVM).

b. Type of data

Two types of data namely instantaneous and RMS values were employed to train the model.

c. Number of features

14 features namely rectified voltage, inverter line output voltages, stator currents and their corresponding THDs, speed instantaneous data were used initially. It was observed through investigation that stator current phasors are sufficient to detect and classify the faults. Hence six parameters namely induction motor stator currents phasors were chosen to train the model for RMS data.

The data was split in the 70-30 ratio. MLP-NN was trained with parameter. MLP accuracy is tabulated as mentioned in Table 2 for an optimum hyper parameter tuning of hidden layers, learning rate, solver, activation function for 14 and 3 features respectively for instantaneous data. SVM accuracy is also tabulated in Table 2 for an optimal hyper parameter tuning of kernel, $\mathrm{C}$ and gamma with 14 and 3 features respectively for instantaneous data. For RMS data with stator current phasors were selected as 6 features where each stator current consists of magnitude and phase angle [13], [14]. The accuracy was found to be $100 \%$ with hyper parameter tuning as mentioned in Table 2.

To evaluate the robustness of the model and to convey the balance between the precision and recall, F1 score was calculated. The F1 score of 0.958 and 0.944 was obtained for 25 classes, 14 features and 3 features respectively representing the accurate classification of different types of faults for an instantaneous data using 
MLP. The F1 score of 0.96 and 0.956 was obtained for 25 classes, 14 features and 3 features respectively representing the accurate classification of different types of faults for an instantaneous data using SVM.

Table 2. Optimum hyper parameters for instantaneous and RMS values

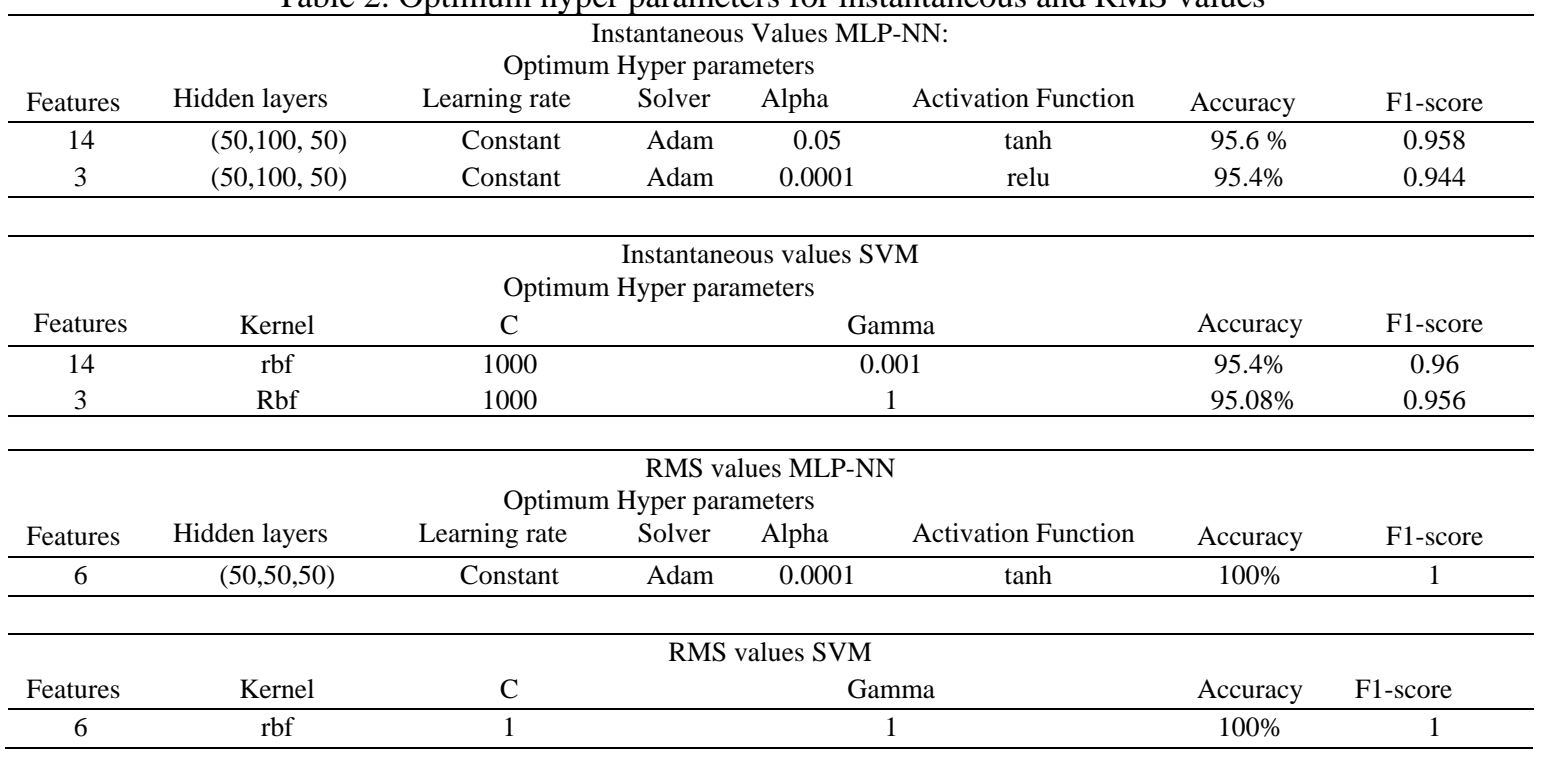

The F1 Score of 1 was obtained for all 25 classes with accurate classification of different fault types, location and severity for RMS stator current phasors using MLP and SVM in comparison with instantaneous data the limitation of the instantaneous value method is the voluminous data and the computation time. Though the accuracy was found to be greater than $95 \%$, it was a pattern-based approach. Hence, another approach which was used for training and testing the model was by using RMS values of the magnitude of stator currents only. But the accuracy was limited to only 51\% in both MLP and SVM algorithms. Hence, stator current phasors were considered for training and testing the model. The model was simulated for all 25 classes of faults with voltage ranging from $390 \mathrm{~V}$ to $426 \mathrm{~V}$ for $0.5 \mathrm{HP}$, squirrel cage 3 phase induction motor rated for $415 \mathrm{~V}$, $50 \mathrm{~Hz}$.

From the number of case studies carried out, it was observed that minor faults are detected as distortion in the concordia patterns of stator currents. The performance of the AC drive system is significantly captured by the phasor stator currents flowing in the circuit as observed by the two-dimensional stator currents obtained by Clarke's transformation. A plot of current concordia patterns for different types of electrical faults in voltage source inverter are as shown in Figure 5 (a) to Figure 5 (e). It can be observed that concordia patterns are distinct for each type of fault. Hence, the phasor stator currents carry the signature of the faults and can be effectively used for detection and classification of faults [4], [25][26].

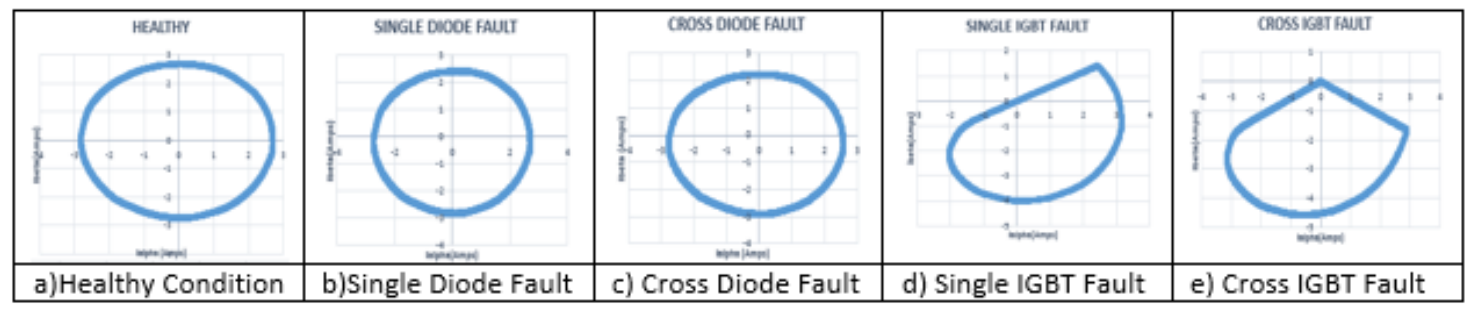

Figure 5. Current concordia patterns for different types of electrical faults in voltage source inverter

The computational training time for the instantaneous values was more than one hour using MLP algorithm to obtain accurate classification of faults as more number of hyper parameters are to be tuned due to voluminous data. The computational training time for the RMS values was 12.38 minutes for MLP and 18.52 seconds for SVM. The stator current phasor approach was found to be more beneficial even for practical 
implementation as it involves minimal number of sensor data. Both MLP and multiclass SVM gave accurate results of $100 \%$ with exact detection, classification and location of the faults. Since the input is taken over a wide range and number of case studies have been conducted with different parameter sets for SVM and MLP, the $100 \%$ accuracy cannot be attributed to overfitting. Rather it indicates the efficacy of the method and the nature of data collection. Multi class SVM is more preferable than MLP for fault detection and classification as the computational time is less.

\section{DEVELOPMENT OF DIAGNOSTIC TOOL}

After an accurate detection and classification of faults, it is essential to take corrective measure to avoid catastrophic effects to the system. Hence a diagnostic tool was developed using TKinter package in python to visually display the information to the operator. In Diagnostic Tool, the RMS values of stator currents, inverter line output voltages along with the waveforms, Concordia current pattern and the speed plot are displayed.

\subsection{Case studies}

\subsubsection{Healthy condition}

The diagnostic tool for the healthy condition of the VSI driven induction motor is as shown in the Figure 6 (a) and Figure 6 (b). The RMS values of the currents and voltages are balanced. The current concordia pattern for healthy system with PWM-VSI driven induction motor is found to be regular symmetrical pattern along iBeta axis and the speed is also found to be constant. Prediction fault type and location are displayed null.

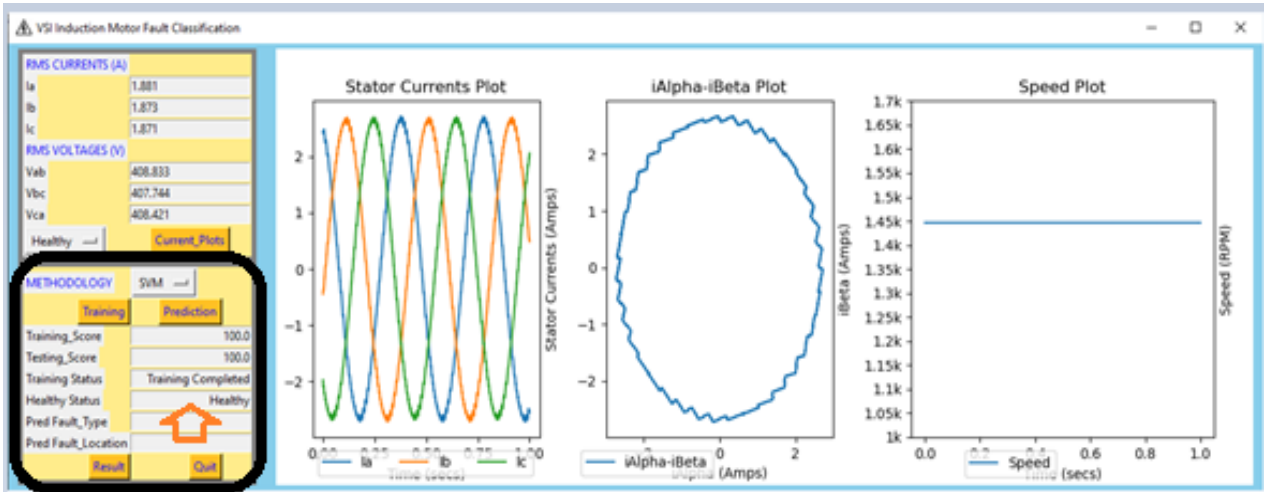

(a)

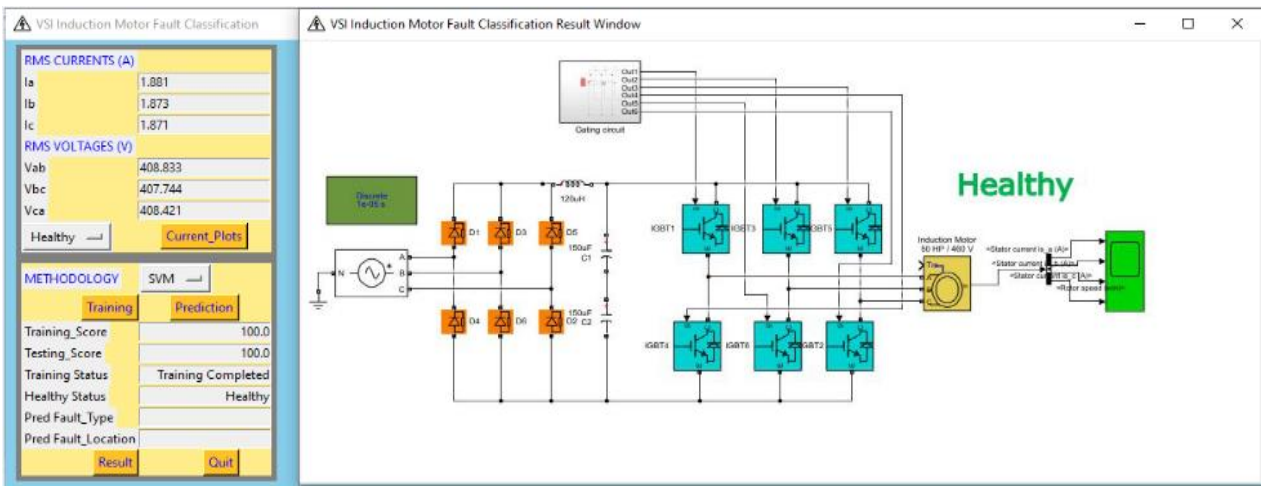

(b)

Figure 6. Healthy condition of VSI driven induction motor

\subsubsection{Single IGBT open fault}

The diagnostic tool for the single IGBT open fault condition of the VSI driven induction motor is as shown in the Figure 7(a) and Figure 7(b). The RMS values of the currents and voltages are unbalanced. The current Concordia pattern for IGBT open fault with PWM-VSI driven induction motor is found to be 
asymmetrical and the speed is also found to be fluctuating affecting the load. Prediction fault type and location are displayed exactly. IGBT5 is the third leg upper switch which conducts during positive half cycle. In case of IGBT5 open fault, it can be clearly visualized that the positive half cycle of phase $\mathbf{c}$ stator current is missing in the waveforms.

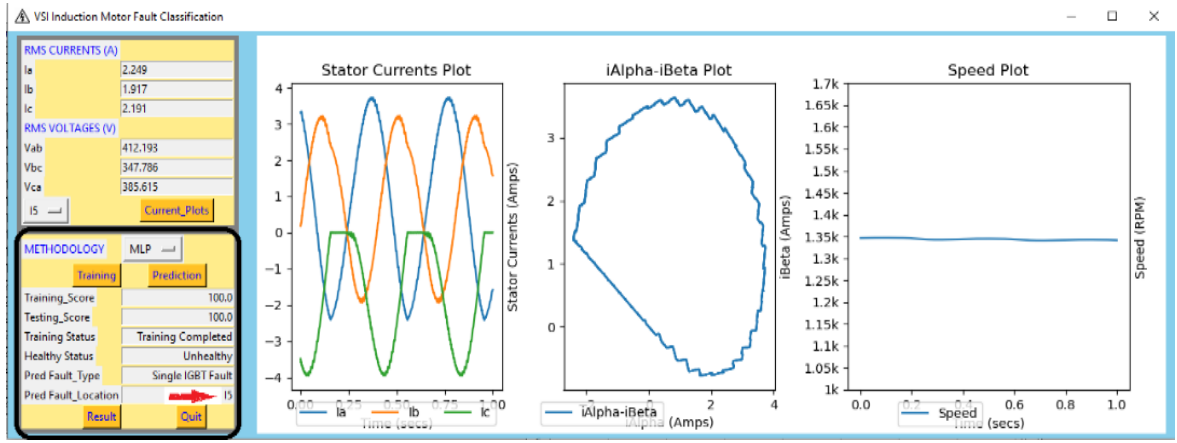

(a)

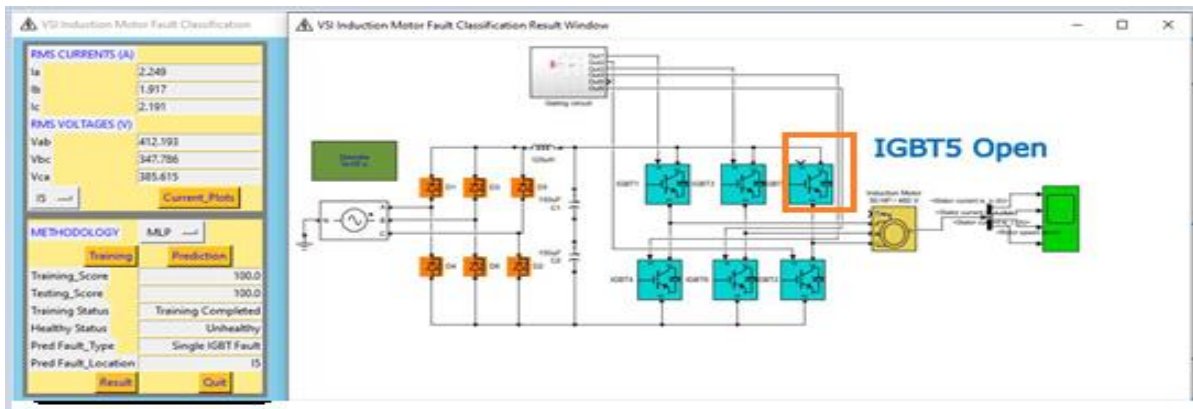

(b)

Figure 7. Unhealthy condition fault prediction for IGBT5 open fault

\subsubsection{Cross IGBTs open fault}

The diagnostic tool for the cross IGBT open circuit fault condition of the VSI driven induction motor is as shown in the Figure 8 (a) and Figure 8 (b). The RMS values of the currents are unbalanced and the inverter line output voltages are also unbalanced which causes increased vibration in the induction motor leading to severe damage if existed for a long run and also increased THDs leading to power quality issues. The current concordia pattern for IGBT open fault with PWM VSI driven induction motor is also found to be asymmetrical and the speed is also found to be fluctuating affecting the load. Prediction fault type and location are displayed in the tool. IGBT3 is the second leg upper switch which conducts during positive half cycle. In case of IGBT2 and IGBT3 open fault, it can be clearly visualized that the positive half cycle of phase $\mathbf{b}$ and negative half cycle of phase $\mathbf{c}$ inverter output currents are is missing in the waveforms.

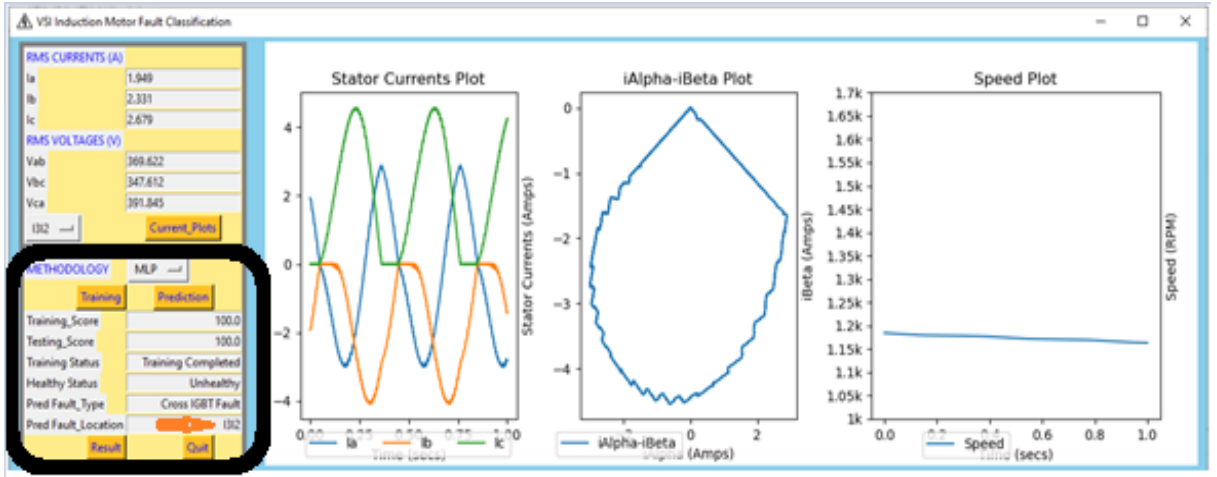

(a) 


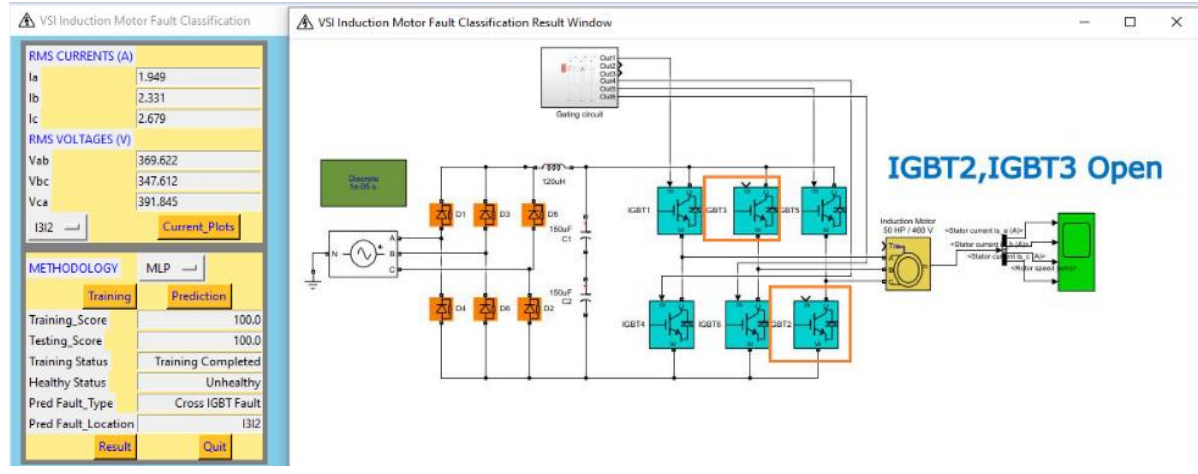

(b)

Figure 8. Unhealthy condition fault prediction for IGBT3 and IGBT2 open fault

\section{CONCLUSION}

Robust and accurate fault diagnostic tools have been developed for faults in the induction motor. However, in modern power electronic drives, there is a need to develop a diagnostic tool for detection of faults in the Power electronics circuit. These faults are not easily predictable, as the induction motor often continues to run. They may lead to catastrophic effects. Hence, an early detection is necessary. In this work, details of Detection and classification of faults in inverter driven induction motor are presented using MLP-NN and multiclass SVM. Different sets of features were investigated using both instantaneous values and RMS values of inverter output line voltages and induction motor stator currents. When instantaneous values were used, the three stator currents carry the signature of various faults and are sufficient to correctly classify them. However, the data is voluminous and the computation time is also high. An alternative to use of instantaneous values is use of RMS values of stator current phasors. The accuracy is also found to be 100 percent with minimal features and a diagnostic tool is developed as an indicator to the operator. The laboratory prototype developed for monitoring the power electronics circuitry with minimal sensors has also been presented. The work would be effective in realising the concept of reliability centred maintenance. Further extension of the work is being carried out using PCA for high dimensionality reduction.

\section{REFERENCES}

[1] Shu-Ying Li, and Lei Xue , "Motor's early fault diagnosis based on support vector machine," AMIMA 2018 IOP Publishing, IOP Conf. Series: Materials Science and Engineering 382 (2018) 032047, pp 1-4, 2018 DOI:10.1088/1757-899X/382/3/032047

[2] Khireddine, M.S. Slimane, N. Abdessemed and Yassine Makhloufi, M.T, "Fault detection and diagnosis in induction motor using artificial intelligence technique," MATEC Web of Conferences, 2014, vol 16, pp. 1-5, DOI: 10.1051/matecconf/20141610004.

[3] Furqan Asghar, Muhammad Talha, and Sung Ho Kim, "Comparative study of three fault diagnostic methods for three phase inverter with induction motor," International Journal of Fuzzy Logic and Intelligent Systems, vol. 17, no. 4, pp. 245-256, December 2017, DOI: 10.5391/IJFIS.2017.17.4.245.

[4] Faeka Khater, Sebah M. I., and Osama M, "Fault diagnostics in an inverter feeding an induction motor using fuzzy logic," Journal of Electrical Systems and Information Technology, vol. 4, no. 1, pp. 10-17, May 2017, DOI: 10.1016/j.jesit.2016.10.005.

[5] Shorouk Ossam aIbrahim, khaled Nagdy Faris, and Esam Abo Elzahab, "Implementation of fuzzy modeling system for faults detection and diagnosis in three phase induction motor drive system," Journal of Electrical Systems and Information Technology, vol. 2, no. 1, pp. 27-46, 2015, DOI: 10.1016/j.jesit.2015.03.004.

[6] V. Gomathy and Selvaperumal S, "Fault detection and classification with optimization techniques for a three-phase single-inverter circuit," Journal of Power Electronics, vol. 16, pp. 1097-1109, May 2016, DOI: 10.6113/JPE.2016.16.3.1097.

[7] H. Yang, J. Zhao and F. Wu, "Current similarity based fault diagnosis for induction motor drives with discrete wavelet transform," 2016 Prognostics and System Health Management Conference (PHM-Chengdu), Chengdu, 2016, pp. 16, DOI: 10.1109/PHM.2016.7819841.

[8] Furqan Asghar, Muhammad Talha, Sung Ho Kim, "Neural network based fault detection and diagnosis system for three-phase inverter in variable speed drive with induction motor", Journal of Control Science and Engineering, vol. 2016, pp. 1-12, 2016. DOI: 10.1155/2016/1286318.

[9] Dong-Eok Kim and Dong-Choon Lee, "Fault diagnosis of three-phase PWM inverters using wavelet and SVM," IEEE International Symposium on Industrial Electronics, 2008, pp. 329-334, DOI: 10.1109/ISIE.2008.4676998.

[10] Wei, $\mathrm{Li}, \mathrm{Xu}$, and Huang, "A review of early fault diagnosis approaches and their applications in rotating machinery," Entropy, vol. 21, no. 4, p. 409, Apr. 2019, DOI: 10.3390/e21040409.

Machine learning based multi class fault diagnosis tool for voltage source inverter ... (Jyothi R) 
[11] Ubale, M.R., Dhumale, R.B., and Lokhande, S, "Open switch fault diagnosis in three phase inverter using diagnostic variable method," International Journal of Research in Engineering and Technology, vol. 02, no. 12, pp. 636-640, 2013.

[12] H. Zhao, W. Deng, R. Yao, M. Sun, Y. Luo, and C. Dong, "Study on a novel fault diagnosis method based on integrating EMD, fuzzy entropy, improved PSO and SVM," Journal of Vibroengineering, vol. 19, no. 4, pp. 25622577, Jun. 2017, DOI: 10.21595/jve.2017.18052.

[13] Jlassi, J. O. Estima, S. K. El Khil, N. M. Bellaaj and A. J. M. Cardoso, "A robust observer-based method for IGBTs and current sensors fault diagnosis in voltage-source inverters of PMSM drives," in IEEE Transactions on Industry Applications, vol. 53, no. 3, pp. 2894-2905, May-June 2017, DOI: 10.1109/TIA.2016.2616398.

[14] Jian-jian, Z., Yong, C., Zhang-Yong, C., and Anjian, Z., "Open-switch fault diagnosis method in voltage-source inverters based on phase currents," IEEE Access, vol. 7, pp. 63619-63625, 2019, DOI: 10.1109/ACCESS.2019.2913164.

[15] R. Jyothi, R. Jayapal and K. U. Rao, "Severity and impact of faults on current harmonics in inverter-fed AC drives," 2016 IEEE Innovative Smart Grid Technologies - Asia (ISGT-Asia), Melbourne, VIC, 2016, pp. 401-405, DOI: 10.1109/ISGT-Asia.2016.7796419.

[16] R. Jyothi, Shaik Mohammed Zahid, Mohammed Sufyan Zain, Reshma Begum; Syed Afzal and K. Uma Rao, et al., "Automatic fault diagnosis system for voltage source inverter driven induction motor," 2019 3rd International Conference on Recent Developments in Control, Automation \& Power Engineering (RDCAPE), NOIDA, India, 2019, pp. 477-481, DOI: 10.1109/RDCAPE47089.2019.8979041.

[17] Shalini Vasishta, and KR Rekha, "A Survey: space vector PWM (SVPWM) in $3 \varphi$ voltage source inverter (VSI)," International Journal of Electrical and Computer Engineering (IJECE), vol. 8, no.1, pp. 11-18, February 2018, DOI: 10.11591/ijece.v8i1.pp11-18.

[18] Akhilesh Sharma, Anandh N., and Sarsing Gao, "Modulation index effect on inverter based induction motor drive," International Journal of Power Electronics and Drive System (IJPEDS), vol. 11, no. 4, pp. 1785-1798, Dec 2020, DOI: 10.11591/ijpeds.v11.i4.pp1785-1798.

[19] Amine Mohamed Khelif, Azeddine Bendiabdellah, and Bilal Djamal Eddine Cherif, "Short-circuit fault diagnosis of the DC-Link capacitor and its impact on an electrical drive system," International Journal of Electrical and Computer Engineering (IJECE), vol. 10, no. 3, pp. 2807-2814, June 2020, DOI: 10.11591/ijece.v10i3.pp2807-2814.

[20] Rekha SN, P Aruna Jeyanthy, and D Devaraj, "Relevance vector machine based fault classification in wind energy conversion system," International Journal of Electrical and Computer Engineering (IJECE), vol. 9, no. 3, pp. 15061513, June 2019, DOI: 10.11591/ijece.v9i3.pp1506-1513.

[21] Khadidja El Merraoui, Abdellaziz Ferdjouni, and M'hamed Bounekhla, "Real time observer based stator fault diagnosis for IM," International Journal of Electrical and Computer Engineering (IJECE), vol. 10, no. 1, pp. 210222, Feb 2020, DOI: 10.11591/ijece.v10i1.pp210-222.

[22] Lachtar Salah, Ghoggal Adel, Koussa Khaled, Bouraiou Ahmed, and Attoui Issam, "Broken rotor bar fault diagnostic for DTC Fed induction motor using stator instantaneous complex apparent power envelope signature analysis," International Journal of Power Electronics and Drive System (IJPEDS), vol. 10, no. 1, pp. 1187-1196, Sep 2019, 10.11591/ijpeds.v10.i3.pp1187-1196.

[23] N. F. Fadzail, S. Mat Zali, "Fault detection and classification in wind turbine by using artificial neural network," International Journal of Power Electronics and Drive System (IJPEDS), vol. 10, no. 3, pp. 1687-1693, Sep 2019, DOI: 10.11591/ijpeds.v10.i3.pp1687-1693.

[24] A. O. Di Tommaso, F. Genduso, R. Miceli and G. R. Galluzzo, "Current fault signatures of Voltage Source Inverters in different reference frames," 2016 International Symposium on Power Electronics, Electrical Drives, Automation and Motion (SPEEDAM), Anacapri, 2016, pp. 599-604, DOI: 10.1109/SPEEDAM.2016.7525977.

[25] Yong C, Zhang JJ, Chen ZY, "Current observer-based online open-switch fault diagnosis for voltage-source inverter", ISA Transactions, pp. 445-453, Apr 2020, DOI: 10.1016/j.isatra.2019.09.019.

[26] Chouhan Abhisar, Gangsar Purushottam, Porwal Rajkumar, Mechefske Christopher K, "Artificial neural network based fault diagnostics for three phase induction motors under similar operating conditions", Vibroengineering PROCEDIA 2020,Vol. 30, pp.55-60,Apr 2020,DOI: 10.21595/vp.2020.21334.

\section{BIOGRAPHIES OF AUTHORS}

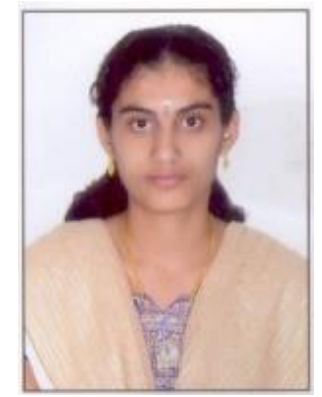

Jyothi $\mathbf{R}$ received B.E in Electrical and Electronics Engineering and M.Tech in Power Electronics From Visvesvaraya Technological University in the year 2009 and 2013 respectively.She is currently pursuing Ph.D in Visvesvaraya Technological University. She has 8 years of teaching experience and currently working as Assistant Professor in Department of Electrical and Electronics Engineering, RV College of Engineering, Bangalore. Her research interests include Power Electronics, Drives and Fault diagnosis using Artificial Intelligence. She has authored 5 articles in the area of Power Electronics and Drives. E-mail: jyothir@rvce.edu.in 

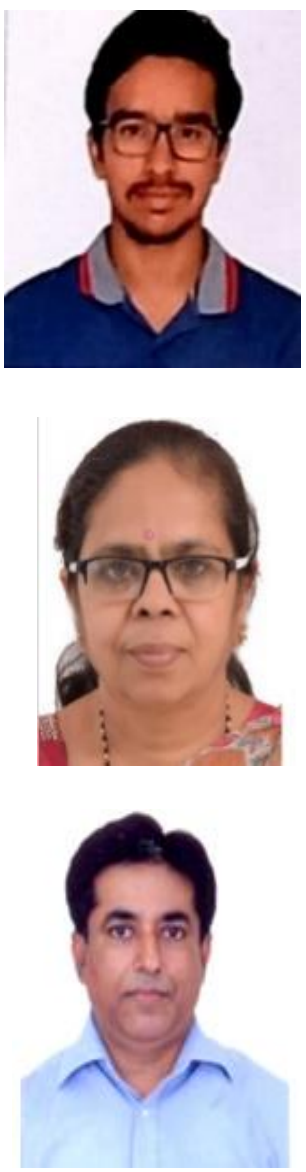

Tejas Holla is pursuing final year B.E in Electrical and Electronics Engineering at RV College of Engineering, Bangalore. His areas of interest include Power Electronics and Drives, Machine Learning, Internet of Things and Embedded Systems.He has also participated in National Level Formula Bharat Electric vehicle engineering design Competition. E-mail: tejasholla.ee17@rvce.edu.in

K Uma Rao obtained her B.E in Electrical Engineering and M.E in Power systems from University Visvesvaraya College of Engineering, Bangalore in 1984 and 1987 respectively. She received her Ph.D from Indian Institute of Science, Bangalore in 1997.She has 32 years of teaching experience and currently working as Professor in department of Electrical and Electronics Engineering, R.V. College of Engineering, Bangalore. Her research interests include FACTS, Custom Power, Power Quality, renewable energy and technical education. Dr. K Uma Rao has published 12 technical books and more than 170 technical publications in national and international journals and conferences. She had also received 11 awards of excellence from various technical societies. E-mail: umaraok@rvce.edu.in

Jayapal $\mathbf{R}$ obtained his B.E in Electrical Engineering and M.E in Power systems from University Visvesvaraya College of Engineering, Bangalore respectively. He received his Ph.D from Vivesvaraya Technological University in 2012. He has 29 years of teaching experience and currently working as Principal at RV Institute of Technology and Management, Bangalore. His areas of interest include Robust control sysytems, loop shaping techniques, real time simulator and robust power system stabilizer. He has authored 20 articles in the areas of Power systems and Power Electronics. E-mail: jayapalr@rvce.edu.in 